\title{
Obligatiestrategieën: een classificatie, en het gebruilk door Nederlandse institutionele beleggers
}

\section{Deel 1: een classificatie van obligatiestrategieën}

Drs. M. Damm

\section{$1 \quad$ Inleiding}

Het door Nederlandse institutionele beleggers, zoals daar zijn pensioenfondsen, verzekeraars, en beleggingsfondsen, te beheren vermogen groeit nog steeds. Begin 1993 was meer dan $780 \mathrm{mld}$. aan de zorgen van deze beleggers toevertrouwd (bron: CBS). Het aandeel van bovenhands verhandelbare vastrentende beleggingen neemt hierin een steeds belangrijker plaats in. Het relatieve aandeel van bullet staatsobligaties, welke het leeuwedeel van deze categorie behelzen, groeide in de portefeuilles van 9\% in 1980 tot bijna 20\% in 1992 ( $\pm 150 \mathrm{mld}) .{ }^{1}$ De absolute omvang van het in deze instrumenten belegde bedrag, alsmede het toenemende relatieve aandeel ervan in portefeuilles, nodigt uit tot het bekijken van de strategieën welke kunnen worden gevolgd met deze instrumenten. Een strategie omvat een verzameling beslissingsregels die samen de acties beschrijven die onder bepaalde omstandigheden dienen te worden genomen teneinde een beleggingsdoelstelling (verder: doelstelling) te behalen. Zoals ook uit dit artikel zal blijken, is het aantal mogelijke strategieën legio, en is hierdoor het maken van een verantwoorde keuze maar al te moeilijk. Om het maken van een dergelijke keuze te vereenvoudigen zullen wij in dit artikel een classificatie beschrijven voor obligatiestrategieën die door Nederlandse institutionele beleggers in de praktijk (kunnen) worden gebruikt. Vervoigens zullen wij bekijken welke van de strategieën die behoren tot de klassen die volgen uit de door ons voorgestelde indeling ook daadwerkelijk gebruikt worden door Nederlandse instiutionele beleggers.

Dit artikel is hiertoe opgesplitst in twee delen Het onderhavige deel bevat de paragrafen 1 tot en met 4. Deel 2 verschijnt in het volgende nummer en bevat de paragrafen 5 en 6 . De verdere indeling is als volgt. In paragraaf 2 beschrijven wij het belang dat vastrentende beleggingen in de portefeuilles van de door ons onderzochte groep beleggers inneemt, en de doelstellingen die met behulp van vastrentende belegging kunnen worden nagestreefd. In paragraaf 3 wordt een classificatie gegeven van de verschillende strategieën die binnen het kader van de door ons gestelde voorwaarden kunnen worden gedefinieerd Paragraaf 4 gaat in op het verschil tussen enerzijds de mate waarin een strategie aansluit op een doelstelling, en dus bruikbaar is, anderzijds de mate waarin strategieën toepasbaar zijn in het licht van de omstandigheden zoals deze voor de belegger en de markt waarop hij

Drs. M. Damm studeerde Economie in Groningen; is sinds november 1988 als universitair docent Financie ring en Belegging verbonden aan de $R \cup G$ 
opereert gelden. In paragraaf 5 wordt beschreven hoe deze omstandigheden door Nederlandse Institutionele beleggers worden ervaren, en de mate waarin zij bekend zijn met en gebruik maken van de door ons genoemde strategieën. Deze informatie is ontleend aan een in 1992 gehouden enquête onder Nederlandse institutionele beleggers.

In paragraaf 6 tenslotte zal een aanzet worden gegeven tot een discussie over het feit of het (niet) gebruiken van strategieën op de juiste gronden gebeurt, en hoe kan worden beoordeeld of wellicht andere strategieën beter passen bij de karakteristieken van de door ons gekozen groep beleggers.

\section{Doelstellingen voor beleggen in staatsobligaties in Nederland}

In het afgelopen decennium heeft zich binnen de beleggingscategorie van vastrentende waarden een verschuiving voorgedaan van onderhandse leningen naar ter beurze verhandelbare (staats)obligaties. De omvang van de laatstgenoemde groep beleggingsinstrumenten in de portefeuilles van institutionele beleggers betrof eind 1991 f $149 \mathrm{mld}$. Dit komt neer op een toename van het relatieve aandeel in de totale portefeuille ten opzichte van 1980 van $11 \%$ tot $19 \%(73 \%)$ hetgeen deze groep tot de sterkst groeiende maakt. ${ }^{2}$ De door ons gehouden enquête wijst uit dat meer dan 90\% van de beleggingen in ter beurze verhandelbare obligaties wordt gedaan in bullet staatsobligaties.

De aandacht voor beleggingen door institutionele beleggers wordt (mede) gerechtvaardigd vanuit het maatschappelijke belang dat door de beheerders van deze gelden wordt gediend. Wij stellen dat de toekomstige welvaart en de hiermee samenhangende economische stabiliteit voor een belangrijk deel afhankelijk is van het succes waarmee de aan instiutionele beleggers toevertrouwde gelden worden beheerd. Dit succes is mede athankelijk van de mate waarin aan de doelstelling wordt voldaan. De voor het vastrentende deel van de portefeuille geldende doelstelling is doorgaans ${ }^{3}$ een afgeleide van de doelstelling zoals deze voor de gehele instelling is gesteld. Het verband tussen beide doelstellingen wordt gelegd in het beleggingsplan.

Kenmerkend voor het naleven van de doelstelling is dat de beslissingen die dienen tot het naleven van de doelstelling, onder onzekerheid worden genomen, en dat de beslissers slechts beperkte mogelijkheden hebben deze onzekerheid weg te nemen of af te wentelen. In een dergelijke wereld, waar een eenduidige en dominante oplossing voor het beleggingsprobleem niet vlug voorhanden zal zijn, kan een beleggingsdoelstelling worden gesteld in termen van een aspiratieniveau voor relevant geachte beleggingscrteria. Deze gedachte ligt besloten in de 'Behavioral Theory of the Firm' (BTF) zoals beschreven door Cyert en March (Cyert en March (1992)). Twee belangrijke (beleggings)criteria zijn het rendement op de beleggingen en de onzekerheid waardoor dit wordt omgeven. Het rendement bestaat uit de opbrengst die wordt gerealiseerd met de belegging over een bepaalde periode. De onzekerheid omtrent de opbrengsten van een obligatie is van invloed op de kans dat de beleggingsopbrengst over deze periode beneden het voor het rendement gestelde aspiratieniveau blijft. ${ }^{5}$ De kans dat de opbrengsten van een obligatie beneden een geaspireerd niveau blijven bepaalt het risico van deze obligatie. Voor de bepaling van het rendement en het risico van een obligatie ${ }^{6}$ van de door ons gekozen soort is de verantwoordelijkheid van de rente ${ }^{\prime}$ de belangrijkste onzekere factor. De kans dat het rendement beneden het gestelde aspiratieniveau blijft volgt, behalve uit de hoogte van dit gestelde aspiratieniveau, uit de hoeveelheid die van deze obligaties in de portefeuille is opgenomen. de veranderlijkheid van de rente, en de gevoeligheid van de waarde van een obligatie voor een renteverandering. Deze gevoeligheid van de waarde van een obligatie voor een renteverandering wordt uitgedrukt in de 'duration' van de obligatie. ${ }^{8}$ 
De veranderlijkheid van de rente kan worden uitgedrukt in de volatiliteit.

De aspiratieniveaus voor deze beleggingscriteria zullen worden gesteld in termen van een minimaal gewenst rendement en een maximaal te aanvaarden risico. De uiteindelijke vaststelling van de hoogte van de aspiratieniveaus die behoren bij deze beleggingscriteria zal enerzijds worden beïnvloed door de verplichtingen waarmee de belegger zich geconfronteerd ziet, maar kan ook door concurrentie-overwegingen worden ingegeven (Lanzilotti (1958)). De hoogte van de aspiratieniveaus, alsmede het relatieve belang dat eraan wordt toegekend, zal in de loop van de tijd veranderen. Dit kan bijvoorbeeld door voortschrijdend inzicht van de portefeuillemanager en doordat de omstandigheden op de kapitaalmarkt veranderen.

De geschetste beleggingsdoelstellingen kunnen met behulp van verschillende strategieën worden nagestreefd. Het ligt voor de hand dat sommige strategieën meer geschikt zullen zijn dan andere. In de volgende paragraaf zullen wij hier nader op ingaan.

\section{Een classificatie van obligatiestrategieën}

Een verkenning van de literatuur leert dat de verscheidenheid aan strategieën indrukwekkend is. Wanneer wij een overzicht van het werk van Martin Leibowitz als auteur en van Frank Fabozzi als redacteur bezien (zie Fabozzi (1992)), dan lijkt het dat naar analogie van het spreekwoord 'zoveel hoofden, zoveel zinnen' kan worden gesteld dat iedere portefeuillemanager zijn eigen strategie heeft.

Het werk van Fabozzi is met name interessant omdat hij als redacteur de ideeën van vele in de praktijk werkzame onderzoekers heeft weten te bundelen. Hierdoor zijn de bijdragen van Salomon Brothers Inc, Goldman Sachs \& Co., Kidder Peabody \& Co., Merrill Lynch, en Morgan Stanley and Co. Inc, maar ook de research-inspanningen van institutionele beleggers zelf, voor een breed publiek toegankelijk gemaakt.
Bij het zien van deze veelheid van mogelijkheden kan de vraag worden gesteld welke van deze strategieën in de praktijk het beste zal voldoen, gegeven een bepaalde doelstelling. De ruime hoeveelheid mogelijkheden suggereert reeds dat een direct antwoord op een dergelijke vraag niet één twee drie te geven zal zijn. Teneinde een antwoord op deze vraag mogelijk te maken lijkt het dan ook wenselijk om de beschikbare strategieën in te delen in categorieën. Door het overzicht dat hierdoor ontstaat wordt de mogelijkheid geschapen om met behulp van nader te definiëren tests de inhoud en de resultaten van de strategieën te vergelijken. De uitkomsten van dit vergelijken kunnen vervolgens als ondersteuning worden gebruikt voor de keuze van een strategie.

In de inleiding hebben wij aangegeven dat wij ons beperken tot die obligaties waarvoor de beweeglijkheid van de rente de belangrijkste onzekere factor voor de prijs is. Hieruit volgt dat de criteria op basis waarvan wij de classificatie zullen doorvoeren voor een belangrijk deel verband zullen houden met de manier waarop binnen een strategie met deze beweeglijkheid van de rente wordt omgegaan. Dit brengt ons tot het aanleggen van de volgende drie criteria:

- Allereerst kan worden bezien of, en zo ja in welke mate, bij een strategie gebruik wordt gemaakt van voorspellingen van de hoogte van de toekomstige waarde van de rente.

- Een tweede criterium betreft de vraag of de strategie erop gericht is de waarde van de portefeuille te immuniseren voor de onzekerheid die uit de beweeglijkheid van de rente voortvloeit.

- Tenslotte kan een onderscheid worden gemaakt naar de mate waarin een strategie een dynamische inbreng vergt van de portefeuillemanger, dan wel een statische houding toelaat.

Van de acht klassen die uit deze drie vragen ontstaan zijn er in de praktijk zes levensvatbaar. Wij gaan ervan uit dat de gedachte om actief gebruik te maken van voorspellingen omtrent de toekomstige hoogte van de rente zich niet 
Figuur 1: Een classificatie van obligatiestrategieën

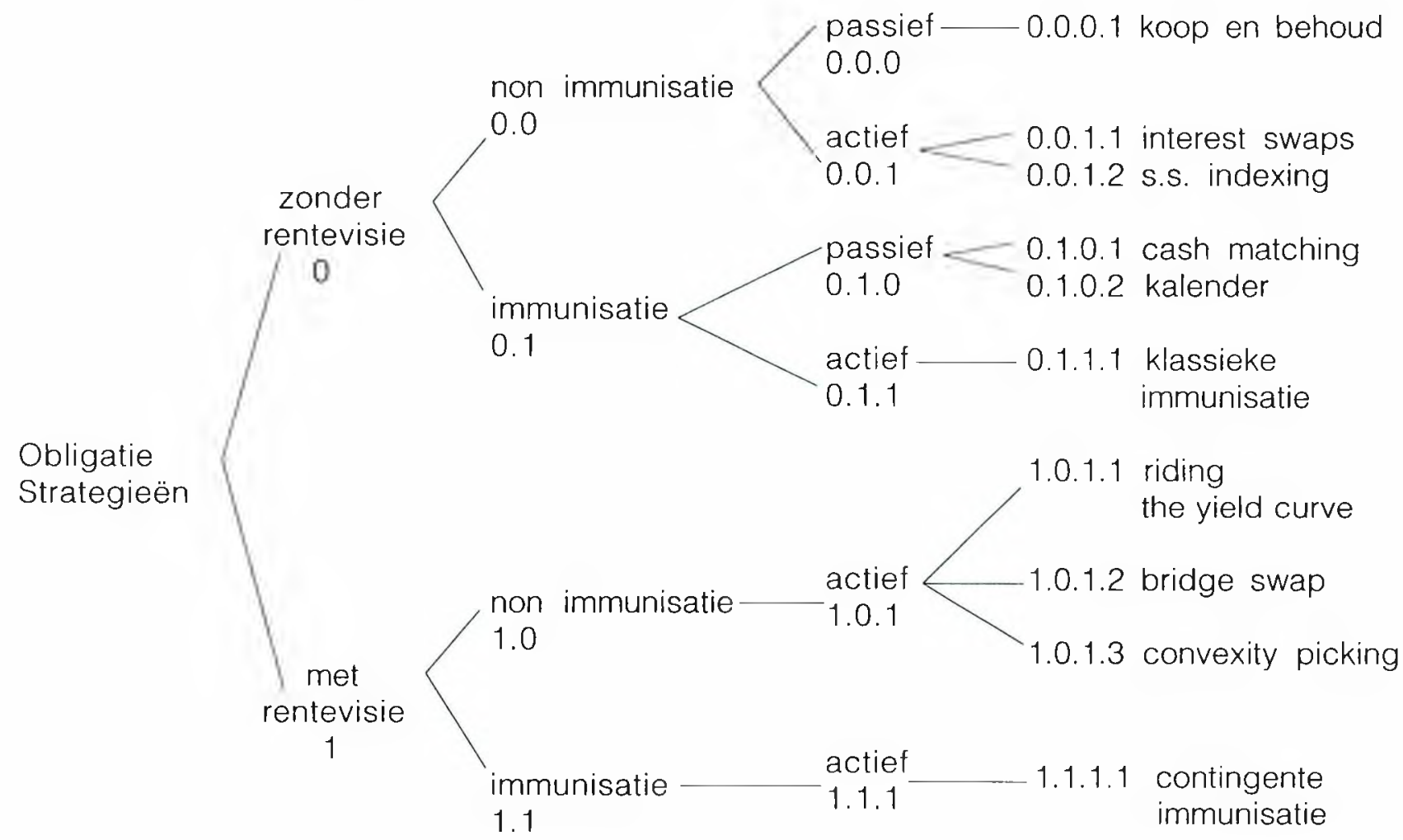

laat rijmen met een statische houding van de portefeuillemanager. Dit geldt zowel voor strategieën waarbij het (ten dele) immuniseren van de portefeuille voor het risico dat voortvloeit uit de beweeglijkheid van de rente ten doel wordt gesteld, als voor strategieën waarbij dit niet het geval is. Hierdoor vallen de klassen 1.0.0 en 1.1.0 af. Indien wij de zes klassen uit deze drie criteria in een figuur samenvatten dan ontstaat de structuur zoals weergegeven in figuur 1 .

In figuur 1 wordt voor de overblijvende klassen één of meerdere voorbeelden van concrete strategieën genoemd. Wij zullen nu de ontstane klassen nader toelichten

Statische non-immunisatie strategieën zonder gebruik van rente voorspellingen (0.0.0)

Deze klasse bestaat uit strategieën die het zonder verdere overwegingen aankopen en aanhouden van strategieën tot het einde van de looptijd omvatten. Strategieën die in deze klasse vallen stammen vaak uit het tijdperk dat obligaties nog voornamelijk als 'koektrommel papier' werden beschouwd. Deze tijd wordt gekenmerkt door de afwezigheid van instrumenten waarmee het renterisico kan worden beheerst.

Het ontbreken van een expliciet in termen van risico en rendement gedefinieerde doelstelling, en een hieraan gekoppelde gedragslijn maakt het moeilijk een oordeel te vellen over het nut van deze strategie-soort.

Het belang van deze strategieën ligt vandaag de dag ook niet zozeer in de concurrerende beleggingseigenschappen die zij heeft, maar veeleer in de mogelijkheden die zij biedt als 'benchmark' (vergelijkingsmaatstaf) voor strategieën die een meer actieve benadering vereisen. Voorbeelden van strategieën die tot deze klasse horen zijn relatief beperkt. De reeds genoemde 'Koop en Behoud' strategie is de belangrijkste. Zij kan zich echter in ver- 


\section{MAB}

schillende vormen aan ons presenteren. De verschillen liggen dan bijvoorbeeld in de soort obligaties waarop de strategie betrekking heeft of de beslissingen met betrekking tot de herbelegging van de vrijvallende gelden.

Voor een beschrijving van het gebruik van de koop en behoud strategie als 'benchmark', zie bijvoorbeeld Barnes (1984).

Dynamische non-immunisatie strategieën zonder gebruik van rentevoorspellingen (0.0.1)

Strategieën in deze klasse zijn bedoeld voor het volgen/verslaan van een 'benchmark.' Deze 'benchmark' kan bestaan uit een publiekelijk bekende index, maar bijvoorbeeld ook uit een door de portefeuillemanager zelf gedefinieerde en geconstrueerde portefeuille. Voor het volgen van een 'benchmark' zijn de zogenaamde 'index tracking' strategieën beschikbaar (Fabozzi (1993)). Voor het verslaan van een 'benchmark' kunnen bijvoorbeeld 'yield pick up' en 'swap' strategieën worden gebruikt (Solnik (1991)).

Strategieën uit deze klasse kunnen behalve individueel, ook als een aanvulling op andere strategieën worden gebruikt, bijvoorbeeld bij de onder 0.0.1 genoemde immunisatiestrategieën. Dit kan door binnen de uit de immunisatievoorwaarde volgende portefeuille-eisen gebruik te maken van de 'yield pick up' en 'swap' strategieën.

Statische immunisatiestrategieën zonder gebruik van rentevoorspellingen (0.1.0)

Strategieën die tot deze klasse behoren hebben als directe doelstelling het immuun maken van de eindwaarde van de portefeuille voor het risico dat voortkomt uit de onzekere veranderingen in de rente.

Dit doel wordt bij strategieën uit deze klasse nagestreefd door de samenstelling van de portefeuille zodanig te kiezen dat de portefeuille, nadat zij voor een eerste keer is ingericht geen nadere veranderingen behoeft. Dit komt erop neer dat voor iedere noodzakelijke toekomstige uitbetaling een belegging voor- handen is in de portefeuille die qua moment van uitbetaling en de omvang hiervan precies aansluit op deze verplichting.

Strategieën uit deze klassen kunnen doorgaans slechts worden toegepast in een markt waarin veel in looptijd verschillende beleggingen voorhanden zijn. Indien een exact op de uitbetalingen aansluitende belegging niet voorhanden is, moet de toevlucht worden genomen tot strategieën uit de volgende klasse. Voorbeelden van strategieën uit deze klasse zijn cash matching (zie Leibowitz (1986)) en de kalender strategie (zie Smith (1990)).

Dynamische immunisatie strategieën zonder gebruik van rente voorspellingen (0.1.1)

Dynamische immunisatie strategieën hebben net als de onder 0.1 .0 behorende strategieën het ongevoelig maken van de eindwaarde van de portefeuille voor tussentijds optredende veranderingen in de hoogte van de rente. In geval van de tot deze klasse behorende strategieën geschiedt dit door de inhoud van de portefeuille regelmatig aan te passen aan veranderende omstandigheden met betrekking tot de rentegevoeligheid van de portefeuille. Het is duidelijk dat deze strategie zal worden gebruikt in geval van afwezigheid van (een aantal van) de onder 0.1.0 genoemde obligaties. De noodzaak van regelmatig aanpassen bestaat doordat de karakteristieken die rentegevoeligheid van obligaties weergeven (zoals de reeds genoemde 'duration') in de tijd verlopen. Een beschrijving van methoden om deze aanpassingen te verrichten, kan worden gevonden in Etzioni (1986), Arnott (1992). Concrete voorbeelden van strategieën die behoren tot deze klasse zijn de barbell-, ladder-, en bullet-immunisatie strategieën. Elk van deze strategieën is erop gericht om door een voor de strategie specifieke combinatie van obligaties de portefeuille te immuniseren voor renterisico. Deze drie klassieke strategieën worden beschreven en met elkaar vergeleken in Ingersoll (1981). 
Dynamische non-immunisatie strategieën met gebruik van rentevoorspellingen (1.0.1)

Deze klasse van strategieën is bedoeld voor het nastreven van een in termen van extra rendement gestelde doelstelling. Dit nastreven gebeurt door te handelen naar door de portefeulle manager geformuleerde verwachtingen omtrent de toekomstige stand van de rente, zonder dat hierbij de intentie aanwezig is het hieraan verwante risico uit te bannen.

Het verschil met strategieën uit de klasse 0.1.1 is dat de activiteiten van de portefeuille manager zich daar richten op verschillen in te verwachten rendement die op dit moment zijn af te leiden uit de prijsverschillen tussen obligaties, terwijl in de onderhavige klasse de activiteiten zich richten op het zoeken en handelen naar uit verwachte veranderingen in de rente te ontstane verschillen in toekomstig rendement.

Drie strategieën die alle drie, zij het op een verschillende manier, gebruik maken van renteverwachtingen zijn riding the yield curve (Dyl (1981)), de bridge swap (Dattatreya (1989)), en convexity picking (Kahn (1990)).

Dynamische immunisatie strategieën met gebruik van rente voorspellingen (1.1.1.)

De doelstelling van tot deze klasse behorende strategieën bestaat uit het behalen van extra rendement onder de randvoorwaarde van de zekerstelling van een minimum waarde van de portefeuille. De bekendste strategie die tot deze klasse kan worden gerekend is de contingente immunisatie strategie zoals beschreven in Leibowitz (1981, 1982, 1983).

Het woord 'contingent' geeft al aan dat het al dan niet immuniseren van de eindwaarde van de portefeuille ergens van afhankelijk is. Deze afhankelijkheid kan bijvoorbeeld bestaan ten opzichte van de tussentijdse waarde van de portefeuille. Pas indien de waarde van de portefeuille een minimumwaarde heeft bereikt, wordt de samenstelling van de portefeuille omgezet zodat deze volledig is geimmuniseerd. Het verschil tussen deze minimumwaar- de en de werkelijke waarde bepaalt de speelruimte voor de portefeuille manager. Hij kan deze gebruiken voor het uitvoeren van meer op het behalen van (extra) rendement gerichte strategieën, zoals de in deze paragraaf genoemde riding the yield curve strategie.

\section{De bruikbaarheid en toepasbaarheid van strategieën}

Wanneer we de strategieën uit de verschillende klassen overzien, dan rijst de vraag welke strategie door een belegger zal worden verkozen, en of sommige strategieën wellicht al op voorhand zijn te prefereren boven die uit andere klassen. Zo lijkt het alsof de verwachte resultaten voor de tot klasse 0.0 .0 behorende koop en behoud strategie altijd zullen worden gedomineerd door de in klasse 1.1.1 genoemde contingente immunisatie strategie. De laatstgenoemde biedt immers een voor een bepaalde horizon gegarandeerd minimum rendement, terwijl de koop en behoud strategie geen enkel zicht biedt op zowel rendement als risico. In deze paragraaf zullen wij hier nader op ingaan. Wij zullen dit doen aan de hand van de stelling dat een strategie die aansluit bij de doelstelling bruikbaar is voor de belegger maar dat dit nog niet betekent dat de betreffende strategie in de praktijk door de betreffende belegger ook kan worden toegepast. De bruikbaarheid houdt verband met de mate waarin een strategie zich in theorie leent om aan de gestelde beleggingscriteria tegemoet te komen. De toepasbaarheid betreft de mate waarin een strategie in de praktijk kan worden toegepast. Dit hangt af van kenmerken met betrekking tot de belegger en de organisatie waarin deze werkt, en van kenmerken van de kapitaalmarkt.

De kenmerken van de relevante belegger omvatten diens kennis, kunde, en mogelijkheden inzake het nemen van beslissingen en acties die horen bij een strategie. Deze hangen samen met de kenmerken die de organisatie betreffen, zoals de omvang van de beleggingsafdeling, het mandaat waarmee de afdeling 


\section{MAB}

werkt, de manier waarop de stand van zaken in de portefeuille en het verloop hiervan in de tijd wordt geadministreerd, de omvang van de portefeuille, de voor de onderneming geldende transactiekosten, en het relevante belastingtarief voor koerswinsten en ontvangen kasstromen.

De derde groep kenmerken betreft de kapitaalmarkt waar de belegginsorganisatie deel van uitmaakt. Deze omstandigheden betreffen de beschikbaarheid van de voor een strategie benodigde obligaties, de hoeveelheid die hiervan verhandeld kan worden, en de regels die bestaan met betrekking tot het kopen en verkopen ervan. ${ }^{9}$

Een en ander kan nader worden toegelicht aan de hand van de aan het begin van deze paragraaf genoemde koop en behoud strategie en contingente immunisatie strategie.

Wanneer we de genoemde kenmerken op deze twee strategieën betrekken dan zal het duidelijk zijn dat contingente immunisatie een actieve betrokkenheid vereist die tot uiting komt in het regelmatig bepalen van de waarde van de speelruimte, en het zonodig ondernemen van relevante actie. Ten tweede zullen de kennis van de verantwoordelijke portefeuille manager, en de technische mogelijkheden van de afdeling waarop hij werkzaam is, op een voldoende hoog niveau staan om het voorgaande te kunnen uitvoeren. Ten derde moet de markt waarin de strategie wordt toegepast voldoen aan bepaalde eisen inzake bijvoorbeeld liquiditeit- en beschikbaarheid van obligaties

Hiertegenover staat dat voor het toepassen van de koop en behoud strategie weinig relevante kennis noodzakelijk is, en de vereisten aan de beleggingsafdeling en de kapitaalmarkt minimaal zijn.

Door dit alles is het dus niet op voorhand mogelijk strategieën uit een bepaalde klasse te prefereren boven andere. Om een oordeel te kunnen vellen moeten tests worden uitgevoerd onder omstandigheden die vergelijkbaar zijn met die van de beleggingsorganisatie die deze strategie wil toepassen. Alvorens dit te kunnen doen moet allereerst een beeld worden gevormd over de in deze paragraaf genoemde kenmerken. Dit zal het onderwerp zijn van het tweede deel van dit artikel.

\section{Literatuur}

AlMR. Performance Reporting for Investment Managers: Applying the AIMR Performance Presentation Standards, Charlottesville 1991. AIMR Publication.

Arnott, R.D., 'Rebalancing: Why? When? How Often? Investment Management Reflections Publication. No. 3 1992

Babcock, G.C., 'Duration as a Link between Yield and Value'. The Journal of Portfolio Management. Spring 1992, pp. 26-35

Barnes T., K. Johnson, D. Shannon, 'A Test of Fixed Income Strategies,' The Journal of Portfolio Management, Winter 1984, pp. 60-65.

Cyert, R.M en J.G. March. A Behavioral Theory of the Firm. 2nd. edition, Cambridge Mass. 1992, p. 42.

Dattatreya, R.E, F.J. Fabozzi, Active Total Return Management of Fixed Income Portfolios, Chicago 1989. Probus Publishing Company Inc.

Haan. J. de, (redacteur), De onderhandse kapitaalmarkt in Nederland, Amsterdam 1991. NIBE publicatie.

Douglas. L G., Bond risk analysis: a guide tot duration and convexity, New York 1990. NYIF.

Dyl. E.A. M.D. Joehnk, 'Riding the Yield Curve, does it work?: The Journal of Portfolio Management. Spring 1981. pp. 13-17.

Etzioni, E.S., 'Rebalance Disciplines for Portfolio Insurance. The Journal of Portfolio Management, Fall 1986, pp. 59-62.

Fabozzi, F.J.. (editor), Investing the complete works of Martin Leibowitz, Chicago 1992. Probus Publishing Company.

Fabozzi, F.J., Bond Markets, Analysis and Strategies, Englewood Cliffs 1993, 2nd edition, pp. 519-523.

ingersoll. J.E., Is Immunization Feasible?. Evidence from the CRSP data, Working Paper nr. 58. Graduate School of Business of the University of Chicago, 1981.

Kahn, R.N., R. Lochoff, 'Convexity and Exceptional Return The Journal of Portfolio Management. Winter 1990, pp. 43-47.

Lanzilottı. R.F., 'Pricing objectives in Large Companies, The American Economic Review, 1958, Vol. 48, pp. 921. 940

Leibowitz, M.L.. 'The dedicated Bond Portfolio in Pension Funds,' Financial Analyst Journal, January/February, 1986.

Leibowitz, M.L.. A. Weinberger, 'Contingent ImmunizationPart I: Risk Control Procedures,' Financial Analyst Journal, November/December 1982, pp. 17-31.

Leibowitz. M.L., A. Weinberger, 'Contingent ImmunizationPart II. Problem Areas,' Financial Analyst Journal. January/February 1983, pp. 35-50.

Leibowitz, M.L.. A. Weinberger, 'The uses of Contingent Immunization,' The Journal of Portfolio Management. Fall 1981. 


\section{MAB}

Smith Jr., C.W., C.W. Smithsm, D. Sykes Wilford, Managing Financial Risk. New York 1990, Herper and Row Publishers.

Solnik, B.H, International Investments, Reading Mass. 1991. Addison Wesley Publishing Company, 2nd. ed. pp. 176-183

\section{Noten}

1 Voor een overzicht en een verklaring van deze en andere ontwikkelingen op de onderhande kapitaalmarkt, zıe: De Haan (1991)

2 Bron CBS 1993, Institutionele Beleggers 1990-voorlopige uitkomsten 1991. Dat tussen 1980 en 1991 het relatieve aandeel van alle tot de vastrentende waarden behorende beleggingen in de portefeuille is gedaald van $70 \%$ tot $60 \%$ ( $\pm f 450$ miljard) is mede terug te voeren op de verhoogde interesse voor beleggingen in zakelijke waarden die hiermee met een relatieve toename van $9 \%$ tot $16 \%(60 \%)$ de op één na snelst stijgende groep zijn.

3 In (bijvoorbeeld) het geval van een beleggingsfonds dat alleen belegt in vastrentende waarden kan de doelstelling voor de vastrentende portefeuille overeenstemmen met de doelstelling van het fonds.
4 Deze methode is beschreven in: Babcock (1992)

5 Een overzicht van de problemen die zich kunnen voordoen bij het vaststellen van het rendement en het risico (de 'performance'-meting), alsmede een handreiking ter voorkoming hiervan, wordt geboden in AIMR (1991).

6 Indien wij spreken van 'een obligatie' dan kan hiervoor, tenzij uitdrukkelijk anders is vermeld, ook 'een portefeuille van obligaties' worden gelezen.

7 In dit artikel zal uit overwegingen van eenvoud worden gesproken van 'de' rente. In de praktijk wordt echter gewerkt met de rentevoeten zoals deze gelden voor de verschillende looptijden. Deze verzameling rentevoeten wordt doorgaans aangeduid met behulp van een termijnstructuur, of indien men de tot een bepaalde looptijd geldende rentevoeten op een bepaalde manier samenvat, de yieldcurve.

8 In de beleggingsliteratuur kunnen vele verfijningen en uitbreidingen van het 'duration' begrip worden gevonden Zie voor een duidelijke uiteenzetting van deze begrippen bijvoorbeeld Douglas (1990)

9 Deze kenmerken zijn verwant aan de uit de financieringsen beleggingsliteratuur stammende begrippen inzake 'perfectie' en 'compleetheid' van de vermogensmarkt, die respectievelijk kunnen worden gebruikt om de mate aan te geven waarin de werking van een markt wordt gehinderd door fricties, en de beschikbaarheid van gewenste beleggingsinstrumenten op deze markt. 